\title{
Pasolini e as locações na Palestina, numa viagem pessoal
}

\author{
Miguel Serpa Pereira*
}

Resumo: Supralluoghi in Palestina é uma experiência cinematográfica singular, na história do cinema documentário mundial. É uma viagem de pesquisa de locações, filmada de modo frontal e direto, que refaz os passos de Cristo, durante a sua passagem pela Terra. Os objetivos de Pasolini vão perdendo o foco das locações e dando espaço para as emoções de estar na Terra Santa, pisando nos chamados lugares santos; com uma equipe mínima, dois sacerdotes como assessores religiosos e três técnicos da empresa de Alfredo Bini. O artigo especula ainda sobre algumas abordagens teóricas tentando fundamentar a proposta.

Palavras-chave: Pasolini, Supralluoghi in Palestina, Evangelho segundo São Mateus.

Resumen: Supralluoghi en Palestina es una experiencia cinematográfica singular en la historia del cine documental mundial. Se trata de un viaje en búsqueda de localizaciones, rodado de modo frontal y directo, que retoma los pasos de Cristo durante su paso por la Tierra. Los objetivos de Pasolini van perdiendo el foco inicial de las localizaciones para dar espacio a las emociones de estar en Tierra Santa, pisando los llamados Lugares Santos. Todo esto, con un equipo mínimo: dos sacerdotes como asesores religiosos y tres técnicos de la empresa de Alfredo Bini. El texto especula, además, sobre algunos abordajes teóricos que fundamentan la propuesta.

Palabras clave: Pasolini, Supralluoghi en Palestina, Evangelio según San Mateo.

\begin{abstract}
Supralluoghi in Palestine is a unique cinematic experience in the history of world documentary filmmaking. It is a location research voyage, recorded in a frontal and direct way, that recreates the footsteps of Christ during His passage through the Earth. Pasolini's goals begin to lose the focus of the locations and give space to the emotions of being in the Holy Land, walking in the so-called Holy places; with a small team, two priests as religious advisors and three technicians from the company of Alfredo Bini. The text also speculates on some theoretical approaches trying to substantiate my proposal.
\end{abstract}

Keywords: Pasolini; Supralluoghi in Palestina; Gospel according to Saint Matthew.

Résumé: Supralluoghi in Palestina est une expérience cinématographique singulière dans l'histoire du cinéma documentaire mondial. C'est un voyage de repérages à la recherche de lieux de tournages, filmé de manière frontale et directe, tout en suivant la trace des pas du Christ pendant son passage sur Terre. Pour ce faire, il est accompagné

* Pontifícia Universidade Católica - PUC-Rio, Departamento de Comunicação Social, Programa de Pós-Graduação em Comunicação Social. 22453-900, Rio de Janeiro, Brasil. E-mail: pereira.ms@gmail.com

Artigo escrito a convite dos Editores.

Doc On-line, n. 21, março de 2017, www.doc.ubi.pt, pp. 41-50. 
d'une équipe réduite composée de deux prêtres, en tant qu'évaluateurs religieux, et de trois techniciens de la maison de production d'Alfredo Bini. Cependant, l'intention première de Pasolini va petit à petit s'éloigner de son projet initial pour céder la place aux émotions de se trouver fouler la Terre Sainte, les pas dans les soi-disant lieux saints. Le texte spécule également sur certaines approches théoriques en essayant de soutenir la proposition.

Mots-clés: Pasolini; Supralluoghi en Palestine; Évangile selon saint Matthieu.

\section{Introdução}

Entre 27 de junho e 11 de julho de 1963, Pasolini se desloca para Israel e Jordânia, com uma equipe técnica e outra de assessoria no campo religioso, para percorrer os lugares por onde Cristo andou. Esse documentário foi uma espécie registro para confirmar o seu projeto de $O$ Evangelho segundo São Mateus, além de ser uma pesquisa para uma possível produção a ser rodada em Israel e Jordânia. Supralluoghi in Palestina é assim um exercício ao mesmo tempo didático, e, no caso de Pasolini, uma certa justificação para a realização de $O$ Evangelho e um argumento contra as patrulhas ideológicas do momento.

Fizeram parte dessa verdadeira trupe de cinema e especialistas no campo exegese bíblica, os seguinte nomes: Da produção cinematográfica Walter Cantatore e Aldo Pennelli da produtora Arco Filme, de Alfredo Bini. Entre os exegetas, o jesuíta Andrea Carraro e o doutor Lucio Settimi Caruso.

Do ponto de vista cinematográfico, é um filme singular. Para Edoardo Bruno, "é um exemplo de cinema direto, de relação entre personagens e realidade, entre objetos e emoções... É um filme-lettre escrito com a câmera. dia após dia, ao longo de um itinerário preciso". (Bruno, Cahiers du Cinéma, n. 169, agosto de 1965). No mesmo artigo da Cahiers, Edoardo Bruno fala de "diário íntimo", talvez uma expressão correta com relação ao filme. Outros conceitos podem ser relembrados, como o de filme-ensaio, ou ainda de experimental etnográfico.

\section{Origem da ideia}

No entanto, Pasolini realizou algo mais complexo e contraditório. Estava vivendo um turbilhão de emoções. $O$ Evangelho segundo São Mateus era um projeto de vida. O episódio de Assis, em que ele teria tido a ideia de fazer o filme, quando viu o Papa João XXIII passando, é apenas uma anedota. Na verdade, estava sim em Assis, não na mesma ocasião, que alias ele não precisa no texto abaixo, quando teve a ideia de fazer um filme sobre o evangelho de São Mateus. Nas suas palavras: 
Foi puro acaso. Estava em Assis, por ocasião de um encontro, a convite de um grupo de padres que queriam discutir comigo o meu filme Accattone, quando comecei a ler o evangelho de São Mateus. Ali pela sexta página, coisa que não me havia ocorrido antes, disse para mim mesmo. Este texto dá um filme maravilhoso! A ideia nasceu assim, de modo espontâneo. (Pasolini Tutte le Opere. Saggi sulla Politica e sulla Società: Milano, 1999: 767).

Não se sabe, ao certo, quando iniciou as pesquisas. Não encontrei registro formal desse início. Sabe-se que a sua leitura dos evangelhos vem da adolescência e primeira juventude. Sua obra escrita é um verdadeiro Continente complexo e contraditório. De qualquer modo, em muitos dos seus textos, podemos encontrar referências diretas e indiretas a esse acento cristão de sua vida. Ele mesmo explica a sua relação com o cristianismo, num texto intitulado Marxismo e Cristianesimo, publicado no suplemento Eco di Brescia, em 18 de dezembro de 1964, sob a inciativa do Circulo Grimau. Sua análise desses dois campos do conhecimento e da vida social que tanto influíram e ainda influem nas sociedades é lúcida e coerente. Lá, por exemplo, ele fala da sua formação cristã e sua passagem para o agnosticismo e a adoção do marxismo. $\mathrm{Na}$ parte referente a uma entrevista, responde com muita segurança sobre todos os temas propostos, incluindo questões relativas ao $O$ Evangelho segundo São Mateus, um filme pelo qual se empenhou com muito conhecimento de causa e realizado para abalar as opiniões.

\section{Viagem à Palestina e analise das sequências}

A viagem à Palestina se situa nesse contexto. Um filme cristão, feito por um agnóstico marxista. Quando se desloca para Israel e Palestina, em 1963, sob o pretexto de buscar locações para $O$ Evangelho segundo São Mateus, já havia definido que faria as filmagens na Itália. Aquela viagem tinha, portanto outros objetivos. Isso fica muito evidente no próprio Supralluoghi. Por outro lado, a escolha do evangelho de Mateus não foi casual. Pasolini a justifica assim:

Antes de mais nada, me parece que Mateus, de todos os evangelistas, é o mais revolucionário, porque é o mais realista, o mais próximo da realidade cotidiana do mundo em que Cristo viveu. A sua narrativa dos acontecimentos, da crise que culmina com a chegada de Cristo, me parece que seja o que melhor corresponde à mentalidade e à situação da gente daquele tempo. (In: Angelini: 2000, 92).

Quando o Cristo adulto entra em cena no Evangelho, o texto de Mateus aparece dito por ele como uma espécie de pensamento articulado e selecionado de uma certa ideologia pasoliniana. Significa dizer que os acentos contidos no evangelho são de Pasolini. São a sua leitura do texto sagrado que dialoga com 
a cultura contemporânea de modo crítico e inovador. É essa força intrínseca da palavra de Mateus que Pasolini seleciona para nos questionar. E, por óbvio, a voz de Enrico Maria Salerno torna a retórica ainda mais convincente. Para melhor precisar esta ideia de que quando Pasolini foi à Palestina não era apenas para definir locações que seriam na Itália, em Luca, Puglia e outros espaços, faço uma análise fílmica das nove sequências do filme.

\section{Sequência número um:}

Ela abre o filme e parece denotar uma surpresa para Pasolini, numa viagem feita antes, mas não vista por nós. Ela se compõe dos seguintes elementos e falas:

Imagem de um camponês palestino (árabe) jogando para o alto a palha para separá-la do grão.

Texto (voz de Pasolini): Veja aquela imagem! Que sorte! Penso que estamos a uns 50 quilômetros de Telaviv. A manhã toda passamos por uma zona rural como a da Itália, muito moderna, industrializada, então, do nada, esta visão. Era isto que desejava encontrar, um mundo bíblico, arcaico.

Intervenção de Dom Andrea: São João Batista referiu-se a esta cena, quando no Jordão pregando, reprendeu os escribas e fariseus. Quando o Senhor vier, com a sua pá limpará a sua eira, recolherá o grão e queimará a palha em fogo inextinguível. Esta é a cena.

Nesta primeira sequência, observa-se a câmera frontal, o que também será observado nas outras. É também o primeiro encontro de Pasolini com palestinos camponeses em ações ancestrais.

Essa paisagem ainda existia em 1996, quando fiz exatamente o mesmo percurso motivado por Soprallluoghi cujo vídeo havia adquirido depois de assistir ao filme no Festival de Berlim de 1983.

A cena é de pura observação e tem a primeira referência a paisagens italianas do mesmo gênero, denotando que a produção do Evangelho estaria sendo armada no Sul da Itália.

Também vale lembrar que o conceito magma estilístico, tirado do seu $\mathrm{Ci}$ nema de poesia, é talvez a expressão mais correta para definir sua forma. Pasolini se referiu a isso dizendo: "eu precisava projetar a alma de um não crente num crente. Isto é o discurso indireto livre. De um lado, uma narrativa pelo olhar de um não crente, porém, por um crente. Uma contaminação estilística, um magma, sob o olhar de Piero della Francesca". Neste particular, percebese também a sua leitura de Auerbach e o seu conhecimentos das relações dele com João XXIII, ainda quando era Núncio Apostólico, em Constantinópula. A relação entre ambos foi muito intensa entre trocas intelectuais e existenci- 
ais. Mas é em Piero della Francesca que ele se inspira para criar os chapéus dos Escribas e Fariseus. São muitas as composição de personagens de fundo pictórico. Isso só enfatiza a sua dedicação ao filme.

\section{Sequência número dois:}

Seguindo em frente, na direção da Galiléia, há uma parada, diante de uma espécie pequena tenda em que decidem o caminho a seguir. Reproduzo parte do texto do filme com apenas uma ou outra intervenção de Dom Andrea nas falas, perfeitamente identificáveis. Pelo texto chegamos às imagens. Pareceme que este processo se aproxima mais do que é o filme.

Próximo, há uma faixa longa, estrita da divisa ente Israel e Jordânia. E assim, embora a Galileia ainda esteja longe... a Galileia á a parte de Israel, da qual o mundo árabe está muito próximo. E, portanto, encontrarmos esta paisagem típica do mundo árabe arcaico. Este sol e esta palha...São elementos perfeitos para representar uma parábola evangélica. Nada teria de ser modificado aqui: aquela tenda, aquele montão de trigo, os gestos deste velho agricultor.

Esta é a passagem do evangelho que se refere ao Monte da Transfiguração, o Tabor. Sete dias depois, Jesus tomou com ele Pedro, Tiago e seu irmão João e os conduziu para um monte alto, a sós.

À direita temos o Lago de Tiberíades. Neste ponto, as minhas esperanças ainda eram grandes. Pensava que Israel, o lugar onde Cristo proferiu sermões poderia ser o lugar perfeito para o meu filme, sem qualquer modificação. Mas, já neste ponto, comecei a suspeitar que neste interior havia algo demasiado moderno, demasiado industrializado. De fato, em pouco minutos, na medida em que seguíamos de Fiat o nosso trajeto até Nazaré em direção ao coração da Galileia, em direção ao lago de Tiberíades vemos uma paisagem contaminada pela modernidade. As pequenas casas brancas dos operários de fábricas, etc. A minha esperança já havia começado a minguar com a minha constatação que certas coisas não eram totalmente como eu as havia imaginado para a cenografia do meu filme.

$\mathrm{O}$ texto segue falando das paisagens da Galileia. Algumas observações iniciais sobre esta segunda sequência. Em primeiro lugar, em diversos momentos, vemos Pasolini anotando algo em dois cadernos diferentes. Sublinho este fato porque Pasolini, em uma de suas falas relativa a Soprallluoghi diz simplesmente que ele não teve qualquer interferência na sua realização. As imagens demonstram o contrário. Há uma cena em que Dom Andrea celebra uma missa na Igreja em que Cristo deu a Pedro o mandato de conduzir os destinos da própria Igreja, episódio narrado por São João e não por Mateus, 
informação dada pelo próprio Pasolini, e ele fica sentado do lado de fora, como a dizer, um agnóstico não vai à missa, e ser coerente com a própria convicção. Depois de passar por Tiberíades, Cafarnaum, chega ao Jordão. Outro episódio muito importante é o diálogo com Dom Andrea às margens do rio Jordão. Este vale a pena citar na íntegra:

Dom Andrea, devo confessar a nossa presença aqui tão rude, tão física... antes da realidade rude do Jordão, tocando as plantas... recostando contra as árvores, embaraça-me, quase tenho um sentido de desrespeito. Sabe em quem penso? Em meus grandes irmãos italianos de outros séculos, os pintores Pollaiolo e outros que pintaram o batismo de Cristo. Eles tiveram que imaginar o Jordão por si mesmos. Para eles, estava tão longe, além dos mares e das montanhas, inalcançável. Para mim está aqui. Agora estou embaraçado, num sentido estético. Mas quanto à sacralidade, à religiosidade cristã, o que poderia me dizer, com um certo distanciamento?

Posso lhe dizer que o Jordão é o ponto de referência histórico e religioso de toda a história hebraica...porque o Antigo Testamento começa com os hebreus cruzando o Jordão e termina com o batismo de João Batista que convidou os hebreus a receberam o batismo no Jordão para se prepararem para a vinda do Messias.

A cena é eloquente por si só. Mas há também a crítica à poluição, ao descaso com que os israelitas tratam o rio da sua história. Fica cada vez mais evidente que este percurso pela Palestina e Israel é uma espécie de viagem iniciática ao mundo cristão e uma comprovação de que esses fatos narrados por Mateus correspondem a uma verdade histórica e sagrada.

$\mathrm{Na}$ análise das próximas sequências, serei mais breve, pois muitas observações se repetem. Tentarei evita-las.

\section{Sequência número três:}

Ela se passa no caminho para Nazaré. Em cena, aparecem o que Pasolini chama de sub-proletariado árabe, as populações drusas e crianças. São imagens muito expressivas que se coadunam, coerentemente, com o filme $O$ Evangelho.

\section{Sequência número quatro:}

Pasolini faz uma digressão e visita um Kibutz que, naquele momento histórico, atraiu muita gente. Era considerada a experiência de socialismo mais avançada. O grupo com quem ele conversa é de italianos, em sua maioria. Faz todas as perguntas para as quais todos gostaríamos de ter respostas. É uma 
sequência extremamente informativa. A questão da educação das crianças sem presença das mães, parece ser a sua principal preocupação. Onde fica o amor de mãe? Quem sabe, não estaria ele pensando no próprio caso. É uma ilação legítima.

\section{Sequência número cinco:}

Trata-se de um texto poético sobre a dignidade dos espaços sagrados. Pasolini parecia emocionado.

\section{Sequência número seis:}

Imagens de crianças árabes.

\section{Sequência número sete:}

Dedicada ao mar Morto, com direito a banhos e meditação.

\section{Sequência número oito:}

Para Jerusalém. Conversa com Dom Andrea. Visões diferentes e variadas, com muita presença árabe, até o Santo Sepulcro. Dom Andrea o questiona sobre o sentido espiritual de sua pesquisa e ele retruca dizendo que não entende como espiritual, pois, não acredita nisso, e sim uma viagem ideológica.

\section{Sequência número nove:}

Para Belém, classificada, por Pasolini, como neo-captalista. O lugar do nascimento próximo do lugar da ascensão.

\section{4. À guisa de uma fundamentação teórica}

Na realidade, com este filme, Pasolini inaugura um gênero documental novo, não classificado nos manuais, e teoriza sobre ele. Algumas fontes mais diretas são por ele elaboradas, mas a origem do conceito conjuga sua própria reflexão sobre o discurso indireto livre, em seu texto Cinema de Poesia. A câmera, cuja presença é sentida o tempo todo, abre o espaço para esse lugar do discurso indireto livre, um dos centros dinâmicos da suas teorias literárias e cinematográficas. É algo ainda bastante complexo, que recebeu de Gilles Deleuze diversas rubricas em seus dois volumes Imagem-movimento e Imagemtempo. Outra fonte é, sem dúvida, o que Pasolini chamava de sacralidade do 
sub-proletariado romano. Significa dizer que $O$ Evangelho é uma das elaborações dessa teoria, exemplificada nas últimas imagens do filme que tanto se referem a Isaias, como à revolução camponesa, com as imagens foices e outros objetos da vida ancestral do campo. Numa das sequências do Evangelho, Adelio Ferrero, comentando a parábola de Accattone diz em relação ao episódio de Madalena:

Também aqui, como na sequência do presságio de Madalena, a música de Bach explode alta, distanciando e acentuando a brutalidade dos fatos, num proceso da sacralidade da angústia e da dor; e a dissolução da situação, com o lento afastamento de Accattone, em primeiro plano, seguido do insulto do outro, se resolve na cruel estação do Calvário. A sugestão do magma é assumida à forma do seu muito querido Auerbach. (Ferrero: 2005, 32).

Pasolini tinha, em Auerbach, um dos seus principais caminhos de raciocínio. Sua familiaridade com o autor alemão é quase pedra angular de suas teorias. Claro que, filosoficamente, percorreu outros autores. Também a função da música, nos nesse conjunto de filmes da sua fase sacra, é absolutamente construtora de sentido. Ora como contraponto às ações, ora como elemento crítico ou ainda como comentário de reforço ao drama. O fato é que Supralluoghi in Palestina continua sem classificação. Embora bem diferente de seu documentário anterior, Comizi d'amore, objeto de um interessantíssimo comentário de Michel Foucault, Supralluogh acaba se beneficiando um pouco dessa primeira experiência, para alguns uma forma de cinema verdade, com o documentário de entrevistas, principalmente no que diz respeito às imagens de crianças. A forma de Comizi d'amore conjuga entrevistas diretas com discussões com intelectuais e especialistas no tem do amor.

\section{Conclusão}

A análise simplificada que fiz acima das nove sequências do filme mostra como complexo é o seu texto. Ao mesmo tempo, revela sua originalidade e espírito cinematográfico, esteticamente envolvente. Considero este trabalho em processo. Não está finalizado. $\mathrm{O}$ tema deve ser revisitado por mim e outros pesquisadores. Não poderia terminar sem dizer algo que já do conhecimento de muitos. No Evangelho, o apóstolo Filipe é interpretado, nada mais nada menos, que por Giorgio Agamben, à época com 22 anos. Consta, inclusive, dos créditos do filme. Gostaria, por fim, de mencionar a ajuda que foi prestada pelo meu amigo e Prof. Dr. Da UFF, José Carlos Monteiro, me cedendo, para consulta suas preciosas fichas, feitas para uma pesquisa sua ainda em andamento. 


\section{Referências bibliográficas}

Agamben, G. (2007). Profanações. São Paulo: Boitempo Editorial.

Angelini, F. (2000). Pasolini e lo spettacolo. Roma: Bulzoni Editore.

Auerbach, E. (1997). Mimesis. São Paulo: Editora Perspectiva.

Barroso, M. Á. (1975). Pier Paolo Pasolini. La brutalidad de la coherencia. Madrid: Ediciones Jaguar.

Bertolucci \& Comilli (1965). Entretien avec Pasolini. Cahiers du Cinéma, Aout, 169: 20-29.

Canziani, A. (1996). Incontri Pasoliniani. Roma: Bulzoni Editore.

Deleuze, G. (2004). A imagem-movimento. Cinemal. Lisboa: Assírio \& Alvim.

Deleuze, G. (2006). A imagem-tempo. Cinema2. Lisboa: Assírio \& Alvim.

Ferrero, A. (1997). Il cinema di Pier Paolo Pasolini. Venezia: tascabili Marsilio.

Joubert-Laurencin, H. (1995). Pasolini. Portrait du poète en cineaste. Paris: Cahiers du Cinéma.

Kactuz, F. (org.) (2014). Pasolini ou quando o cinema se faz poesia e política de seu tempo. Rio de Janeiro.

Lahud, M. (1993). A vida clara. Linguagens e realidade segundo Pasolini. Campinas: Editora da Unicamp.

La Porta, F. (2002). Pasolini. Un gnóstico innamorato della realità. Firenze: Le Lettere.

Mariniello, S. (1999). Pier Paolo Pasolini. Madrid: Ediciones Cátedra.

Moscati, I. (2015). Pier Paolo Pasolini. Vivere e sopravivere. Torino: Lindau.

Murri, S. (1994). Pier Paolo Pasolini. Milano: Il Castoro.

Pasolini, P. P. (1999). Tutte le opere. Saggi sulla politica e sulla società Milano. Arnoldo Mondadori Editore.

Pasolini, P. P. (1999). Tutte le opere. Saggi sulla letteratura e sull'arte, Tomo Primo. Milano: Arnoldo Mondadori Editore.

Pasolini, P. P. (2001). Tutte le opere. Per il cinema, Tomo Secondo. Milano: Arnoldo Mondadori Editore.

Repetto, A. (1988). Invito al cinema di Pasolini. Milano: Mursia Editore. 
Filmografia de Pasolini para esta pesquisa

Accattone, 1961.

Mamma Roma, 1962.

La Rabbia, 1963.

La Ricotta, 1963.

Sopralluoghi in Palestina, 1963.

O Evangelho segundo São Mateus, 1964.

Comizi d'amore, 1963/1964.

La você di Pasolini, Feltrinelli, 2006. 